\title{
OVERVIEW OF THE EXPERIMENTAL DETERMINATION OF ACOUSTIC FLOW ON THE BASIS OF SOUND INTENSITY MEASUREMENTS
}

\begin{abstract}
A large variety of CFD/CAA hybrid approaches are commonly used today for aero-acoustic engineering applications using equations and the coupling between source and acoustic propagation region. The coupling is usually made using Lighthill's acoustic analogies and Kirhchoff's acoustic boundary conditions. This paper intends to give answer how the size and shape of the source may be influence on the accuracy of the different coupling methods and their sensitivity. In this way, some experimental investigation was made using sound intensity measurement technique to the graphic presentation of the spatial distribution of the acoustic power flow over various geometrical shapes of structures located in a three-dimensional space. The results of these studies contribute to the theory of sound and general knowledge about the physics of flow acoustic phenomena, especially in the near acoustic field. As a result of research, the visualization analysis of the sound intensity flux in 3D space is shown as flow wave reactions on the presence of obstacles with different shapes. The results of vector flow fields around a rectangular and circular plate, over the cavity and inside a ducts are shown. The visualization of acoustic power flow in real-life acoustic fields can explain many particular energetic acoustic effects like scattering, vortex flow in shielding area, etc., concerning area where it is difficult to make numerical analysis.
\end{abstract}

Keywords: flow acoustics, sound intensity, sound imaging

\section{PRZEGLA¿D REZULTATÓW BADAŃ PRZEPŁYWÓW AKUSTYCZNYCH WYKONANYCH METODA POMIARU ROZKEADU NATĘŻENIA DŹWIĘKU}

Duża różnorodność hybrydowych zastosowań technik CFD/CAA jest dzisiaj powszechnie używanym narzedziem w inżynierskich zastosowaniach aeroakustycznych wykorzystujacych równania sprzegajace źródło drgań mechanicznych z polem propagacji akustycznej. Sprzeganie tych obszarów odbywa sie zwykle za pomoca akustycznej analogii Lighthilla i akustycznych warunków brzegowych Kirhchoffa. W tej publikacji poszukuje się odpowiedzi, jak wielkość i kształt źródta wptywa na dokładność $i$ wrażliwość różnych metod sprzegania. W tym celu wykonano kilka badań eksperymentalnych z użyciem techniki pomiaru natęzenia dźwięku obrazujac przestrzenny rozktad przeptywu energii akustycznej w otoczeniu przeszkód o różnych kształtach geometrycznych. Jako rezultaty badań przepływów pokazano reakcje fali akustycznej na różnego ksztattu przeszkody wprowadzone w pole przeptywowe. W formach graficznych przedstawiono wyniki badań przepływów wokót płaskiej i okragłej ptyty, nad wnękq akustycznq i we wnetrzach przewodów. Wizualizacja przeptywu energii akustycznej w polach rzeczywistych może wyjaśnić wiele szczególnych efektów akustycznych, takich jak rozpraszanie i tworzenie się wirów za przeszkoda lub podobne reakcje w obszarach, dla których trudno jest budować modele numeryczne.

Słowa kluczowe: przepływy akustyczne, natężenie dźwięku, wizualizacja dźwięku

\section{INTRODUCTION}

In recent years, considerable advances have been made in computational fluid dynamics (CFD), and a number of commercial codes which can be used to predict the behavior of moving air are now available. In principle, these codes could be used to determine the fine details of airflow turbulence around any flow spoiler, and this could then be used to predict the generated noise. In practice, in order to solve the relevant turbulent flow equations with sufficient accuracy, it is necessary to have a three-dimensional computational mesh which is large enough to cover the region of interest (which may be several meters), but with the size smaller than the smallest turbulent motion (eddy) present in the flow (this can be as small as $0.1 \mathrm{~mm}$ in air). In addition, the computations must be made for unsteady flow, utilizing a time-step smaller than that associated with the fastest eddies. This would mean working with elements and the time step so small as to make the computing time required extend over many centuries, hence the direct determination of regenerated noise is impossible with today's technology. Since the direct simulation of a strongly disturbed flow is not practical, CFD codes use 'turbulence models' to represent the small-scale effects of turbulence (Munson et al. 1990, Mak and Oldham 1995). The most popular averaging and filtering operations lead to the Reynolds-averaged Navier-Stokes (RANS) equation, which relies on a statistical average leading to steady computations in the general case.

The second popular filtering approach leads to the largeeddy simulation (LES) technique (Wagner et al. 1989), which is based on a filtering operator that results in unsteady 3D computation. The filtering procedure can be implicitly associated with the application of a convolution filter to the direct numerical simulation (DNS) solution or implicitly imposed by numerical errors, the computational mesh or modelling errors, or even by the blending of these two possibilities. The lack of validation material is greatest in application areas that are new to the use of CFD. Hence, there are often significant and troubling gaps in the validation of CFD.

\footnotetext{
* West Pomeranian University of Technology, Faculty of Maritime Technology and Transport, Szczecin, Poland, e-mail: weyna@zut.edu.pl
} 
As computational fluid dynamics finds application in an increasing number of scientific and engineering disciplines, the validation of the software is often assumed by the user (Hafez and Oshima 1995). However, now that commercial CFD software has the capacity to solve a vast range of engineering problems, the validation material that accompanies it can only apply to a subset of these applications. While academic research may well accompany CFD simulations with experimental campaigns in order to test a new model or solution technique, industrial users often view CFD as just another design tool. The latter are required to assume that the software, if used correctly, produces results that can be relied on (Hargreaves et al. 2007).

\section{NUMERICAL TECHNIQUES IN AEROACOUSTIC FLOWS}

Aeroacoustics is the scientific discipline between fluid mechanics and acoustics. It considers sound generated by aerodynamic forces or motions originating from turbulent flows. Initially, experimental investigations were used to derive some empirical relations in order to estimate the noise emission of new technical products (Richards et al. 2004). However, owing to strongly increased computer performance, the numerical simulation of acoustic fields generated by fluid flow, computational aeroacoustics (CAA) has become a very attractive subject of research (mainly using Fowcs-Williams Hawking acoustic analogies, FWH (Fowcs 1996)). Computational Aeroacoustics is a numerical simulation of noise generation and propagation within aerodynamic flows. A major application of CAA has been towards the prediction of noise generated by aircraft components and the corresponding sound level observed in the far field (fig. 1). Noise generation is governed by the NavierStokes equations, however, the solution of the Navier-Stokes equations over large domains to determine far field noise is not computationally feasible (Gloerfelt et al. 2003). This could become feasible by the separation of the noise generation and noise propagation processes, with noise propagation being determined by the linearized Euler equations (LEE), which are computationally less intensive than the Navier-Stokes equations (Gloerfelt et al. 2003). Even so, very large computational domains are still prohibitive, requiring them to be truncated by the introduction of artificial boundaries.

The optimization of the numerical models requires a thorough understanding and accurate description of the sound propagation in real-life conditions, because a number of relevant aspects of this topic are not covered by the computation models existing today (Crighton et al. 1966). In short, it is not expected that all aspects can be addressed with a single theoretical multiphysics model, therefore all models used should be validated by various experiments. In a real-life acoustic field a main validation experiment may be carried out using a sound intensity measurement and non-invasive laser anemometry optical techniques (PIV, LDA). The laser methods for assessing the dynamics of acoustic flow fields are an effective tool for a non-invasive study of the acoustic fields in a wide range of acoustic particle velocity (Raffel et al. 1998, Zhang 2010). The big advantage of this research is that all the changes in the dynamics of flow structure can be recorded and visualized as a function of time. The evaluation of the space and time of fluctuating velocity and vortices fields can explain the mechanism of the formation of turbulence in the wake area. The study of the interaction of the vortices with the test structure may be very helpful to modify the model.

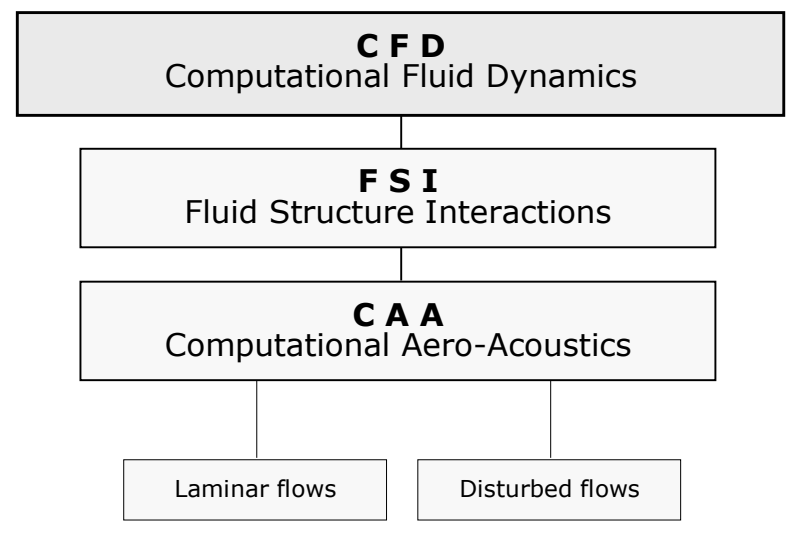

Fig. 1. Numerical techniques for flow dynamics

The experimental sound intensity (SI) measurement technique (Fahy 1989) will constitute a database for the validation, in terms of accuracy and robustness, of different hybrid techniques (CFD/FSI/CAA/LES), even if broadband noise predictions, generated by the inherent 3D nature of turbulence, are unreliable today. Further experimental and numerical research is needed to validate the results and to confirm the usefulness of the method in engineering applications.

The literature seldom contains publications in which the results of analytical model calculations are verified by experimental tests. At its best, such an analysis concerns only a distribution of pressure levels in an acoustic field (Dickinson 1989). However, in a real acoustic field, there is a close connection between scalar and vector effects, represented by the acoustic pressure and particle velocity. In a real acoustic field both scalar (acoustic pressure) and vector (the acoustic particle velocity) effects are closely related. Only when the acoustic field is described by both potential and kinetic energies may we understand the mechanisms of propagation, diffraction and scattering of acoustic waves on obstacles, as a form of energy. Energy distribution images in acoustic fields, with the SI method connected with the graphical presentation of the energy flow (derived from direct measurements) are a new element in acoustic metrology. The introduction of these possibilities has greatly changed the approach to examining many acoustic phenomena. This measurement technique has been applied to various studies on theoretical and applied acoustics, greatly simplifying the methods of research. This is because it does not require criteria as strict as in traditional measurements, and the precision of direct measurements in real-life situations does not vary from laboratory experiments. The measurements can be carried out in a near field (by a laser techniques also in hydrodynamics near fields) and in the fields with a presence of parasite noise. 
This kind of problems will be presented in the present publication. The development of the understanding of the noise generation mechanisms on the basis of Vortex Sound Theory has resulted principally from the testing of the real model in real conditions, and an understanding of the propagation of sound over structures with a complex impedance.

\section{ACOUSTIC FLOW FIELDS}

Many theoretical discussions on an aeroacoustic field distribution consider cases with initial and edge conditions. However, in real systems, wave relationships are so complicated that the introduced edge conditions may cause large discrepancies between the theoretical models and the real ones. Even the initial experiments have proved that routine linearization causes differences between the predicted results and the real image of the field that are too large. The differences are usually either due to far-fetched simplifications, or result from the lack of all necessary data.

Understandably, theoretical descriptions of the acoustic field deal with simplified cases, where it is easy to determine properly the edge conditions to solve the differential equations. Actual acoustic fields, created by a simultaneous action of various wave effects, cannot be fully explained by some general mathematical descriptions. This is why elementary acoustic phenomena are discussed separately, and only in some idealized cases is it possible to apply superposition rules to determine the final image.

A good form of illustration of acoustics phenomena occurring in real conditions is the application of the sound intensity technique. This technique offers the possibility to fully explain the physical meaning of wave phenomena, and makes it possible to consider the mechanisms of propagation, radiation, diffraction or scattering in flow acoustics. The visualization of the vector parameters of the flow wave offers the possibility of a full analysis of acoustic flow fields as an image of the sound intensity stream. A properly used intensity method gives a chance of the measurement of the vector distribution in any place of the restricted space, even within a near field and boundary layer area. At the same time it is a convenient technique, making it possible to verify empirically the field parameters determined by means of CAA methods.

In conclusion, we can say that by the direct measurement of acoustic power flow and a graphical description of the results, one can explain diffraction and scattering phenomena that occur in a real acoustics flow field. The application of the sound intensity technique, together with CFD/CAA methods, has improved the quality of acoustic diagnostics and makes it possible to visualize energy wave phenomena as the acoustic field around the structure.

\section{VISUALIZATION OF ACOUSTIC ENERGY FLOW IN SPACE}

Until the last decades the study of vector acoustic fields and noise flow visualisation in the acoustical practice has been quite rare. Flow visualization has been widely applied in simulation and experimental studies; numerical computer tech- niques are used for flow visualization in fluid mechanics and aerodynamics studies. CFD methods, along with the development of numerical methods and the increase in processor capacity, constituted to the appearance of a new type of relevant ready-made software (Fowcs 1996, Gloerfelt et al. 2003). Visualization systems, by serving a dual role as a provider of exploration and exposition capabilities have become indispensable for the analysis of CFD results. Also, developments in visualization algorithms, managed by complex databases, the progress in computer graphics, multimedia technologies and network communication, all contribute to the development of flow visualization techniques.

Modern forms of acoustic flow visualization are often quite different. One can use a traditional distribution of vectors in the form of arrows, isosurface distribution maps or streamlines (pathways where the flow takes place). Flows shown in two- or three dimensions are created by the available graphic systems that give the user the ability of choosing the most convenient presentation form (Crighton et al. 1966, Raffel et al. 1998).

Sound intensity amplitude may be determined by: a twomicrophone method, cross correlation transform between pressures from two microphones, and as a direct measurement of pressure and acoustic particle velocity. The aforementioned advantages of the SI technique may be used in acoustic metrology much more effectively if a three-dimensional intensity probe is applied. The 3D USP Microflown Ultimate Sound Probe is a new type of sensor, used as a practical SI transducer. It is a very compact and integrated sound probe that combines three orthogonally positioned particle velocity sensors and a miniature pressure microphone. The USP, used as a scanning probe, was especially developed for measurements carried out very close to vibrating objects - the source of acoustic power. The actual sensor configuration without its cap is less than $5 \mathrm{~mm}$ $\times 5 \mathrm{~mm} \times 5 \mathrm{~mm}$. The USP effectively extends the traditional possibilities for complete sound intensity depictions of 3D energetic fields, by measuring three particle velocity vector components and the acoustic pressure. By minimizing the array distance to the sound source, one can investigate particle velocity levels in very near field conditions (a so called hydrodynamic region), and the power acoustic flow may now be fully described in real-life experimental conditions.

The sound intensity method applied in acoustic metrology simplifies the measurement technique of acoustic power and effectively replaces classical methods (Hargreaves et al. 2007, Richards et al. 2004). Wave phenomena registered in the region of the sources working in their natural environment allow one to analyse the field both qualitatively and quantitatively, i.e., to evaluate its energetic distribution and to visualize the wave distribution in the tested area. One of the main advantages of the SI technique is the possibility of identifying the energy radiated from different parts of the radiating structure. This is a crucial asset in tests involving industrial acoustics.

The main advantages of research carried out with a sound intensity technique consist in the fact that the measurements taken refer to energy dependencies of the field, and that they can be carried out under real conditions. 
As has already been pointed out, the advantages of the SI technique may be used in acoustical measurements much more effectively than classical methods, e.g., in verifying the theoretical methods of CAA modelling with check measurements taken under real conditions. The tests on real systems and the presentation of the results in graphical form show that the application of the principles of the superposition of field phenomena in theoretical methods of acoustic modelling should be taken with great care. The investigations have shown that in reality the turbulent character of the acoustic wave may cover all the compartment space; thus it can reach beyond the area attributed mainly to the acoustic near field.

The presentation of pathways on which the acoustic energy is conveyed, is especially useful in the visualization of complex acoustic sources (machine diagnostics, radiation of vibrating inhomogeneous structures) and in explaining their action in real-life conditions. It is a form of a qualitative analysis that appeals directly to the imagination; the observation of acoustic wave distribution in the air and the assessment of wave reaction on the obstacles and acoustic barriers in their way becomes more tangible and helps in complementing the theoretical knowledge of non-linear phenomena occurring in acoustic fields (see the author's publications (Weyna 2009a, b, 2010a, b, 2011, 2012a, b, 2013, 2014).

\subsection{Flow wave reflected from a hard plate}

The aim of the first tests with the SI measurement was to describe the distribution of sound intensity vectors in the reflected field of an acoustically hard surface. The field distribution was measured in $1 / 3$ octave frequency bands from $80 \mathrm{~Hz}$ to $5 \mathrm{kHz}$. Some examples of the field pictures are shown in figure 1. The wave source was a small loudspeaker supplied with white noise, which generated oblique waves at an angle of $60^{\circ}$ to the plate, from a distance of $1.3 \mathrm{~m}$. The tests on the reflected field were carried out in a measurement plane of $2.1 \mathrm{~m}$ by $1.2 \mathrm{~m}$ placed in the semi anechoic room. The measurement plane was divided into 630 elementary surfaces, in the middle of which were measured the sound intensity components $x y$ (fig. 2a). Geometrical-added, mutually perpendicular components xy are presented as a distribution of intensity vectors (arrows) with a colour map of intensity distributions. The component amplitudes keep proportionality in compliance with the arrow length. Additionally, a graphic analysis of the reflected field may include a 3D picture of streamlines and intensity isosurface (level $82 \mathrm{~dB}$ ) of the scattered sound intensity flux. It is a form of qualitative analysis for stationary reflected fields, which consists in a complex evaluation paths, along which is transported the acoustic energy.

Comparing the field distribution for the whole frequency band tested, it can be stated that the nature of the resultant field is really complex. With oblique incident sound, it can be stated that it is not possible to find any relationship between the nature of the reflected wave distribution and the geometric law of reflection (see the white lines in fig. 2a). For most frequency cases, there appears an acoustic shear layer close to the reflecting surface and there exists a separated area of the clash between a direct wave and a reflected wave, which, in the distribution picture, is shown in the form of a distinct saddle point. For lower frequencies, it can be noticed that violent flows form in the form of an acoustic wave vortex.

\subsection{Rectangular plate and a circular disc inside a 3D field}

The next examples illustrate how the application of the SI measurement can be of help in the solution of practical problems of acoustical diagnostics and noise abatement. These tests concern the application of the sound intensity technique to the graphic presentation of the spatial distribution of the acoustic energy flow around a flat, hard-acoustics rectangular plate with dimension $0.52 \times 0.32 \mathrm{~m}^{2}$ and thickness $25 \mathrm{~mm}$, located in an anechoic chamber, and excited by an axially travelling incident wave (stationary broad band pink noise), coming from a loudspeaker at a distance $0.6 \mathrm{~m}$ central to the plate. The measurements using a USP intensity probe have been carried out in a one-third- and one-twelfth octave bands and a vector map has been built in the frequency range between $25 \mathrm{~Hz}$ and $6300 \mathrm{~Hz}$. The SI measurement was taken step by step with a fixed-point method.

Some of the results are shown in figure 3 in the form of the distribution of streamlines of the sound intensity field in a plane close to the rectangular plate. Note should be given to the vortex effects in the shadow side of the plate.

Figure 4 shows examples of the vector field distribution. Using different methods of the presentation of the results one can see the scattering effects and the acoustic shadow formed in the 3D space in the rear side of the plate (fig. 4a). In the second part of our research, the investigations of sound intensity stream distributions will be made in the space around one corner of the plate. In the image of the energetic acoustic field one can notice the intensity streamlines in ribbon form in the three-dimensional space close to the lower corner of the plate (see fig. 4b). Figure $4 \mathrm{c}$ shows an example of an intensity isosurface around the plate.

Figure 5 presents a scattered field formed around an acoustically hard disc $0.6 \mathrm{~m}$ in diameter. The disc acts as a reflecting and scattering shield and it is easily noticed that the wave flows around as intensity streamlines, the shape of the wave behind the disc and the intensity isosurface. Note how these streamlines form a circular pattern surrounding each primary vortex close to the rear side of the models. The shadow area represents the focusing of sound energy. Such a phenomenon could not be observed by using pressure data to represent the acoustic field.

\subsection{Acoustic flow around a cavity}

The next example presents an experimental study of sound intensity stream flow over a flat plate with a rectangular deep cavity $(0.2 \mathrm{~m}$ wide and $0.5 \mathrm{~m}$ deep - coefficient $L / D=0.4)$.

An experimental model was build for the prediction of the occurrence of tones due to the coupling between the shear layer instabilities and the acoustic response of the cavity. 
a)

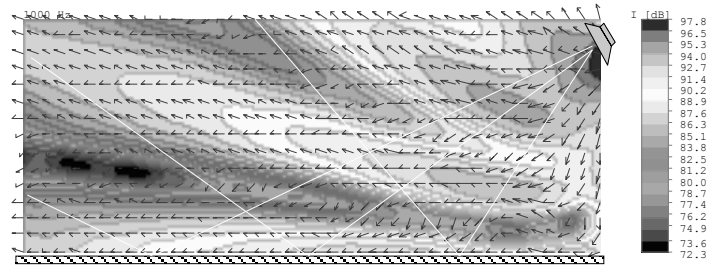

b)

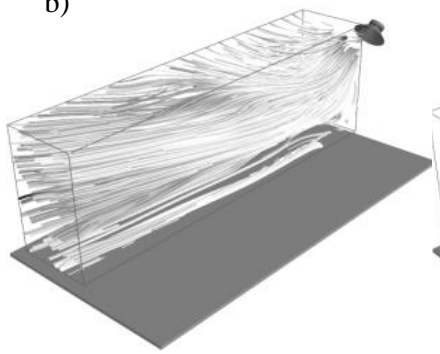

c)

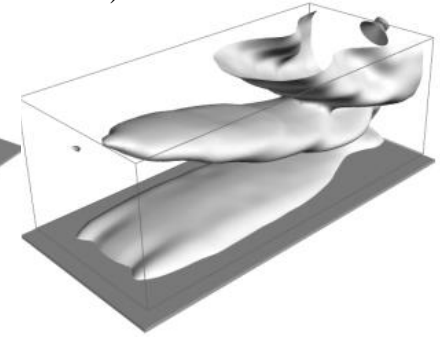

Fig. 2. Sound intensity wave reflected from a hard plate - acoustic source - loudspeaker oblige $60^{\circ}$ : a) intensity vectors map, b) intensity streamlines in half measured space, c) intensity isosurface

Before the plate

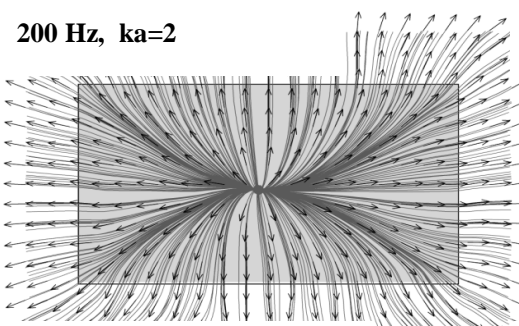

$1000 \mathrm{~Hz}, \mathrm{ka}=10$

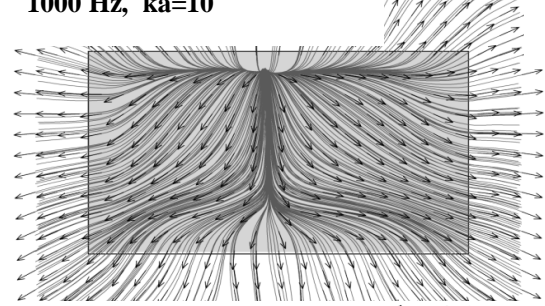

$2000 \mathrm{~Hz}, \mathrm{ka}=\mathbf{2 0}$

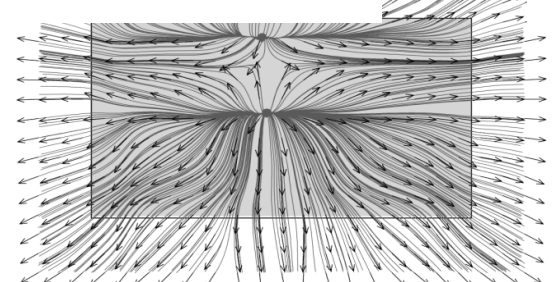

Beyond the plate

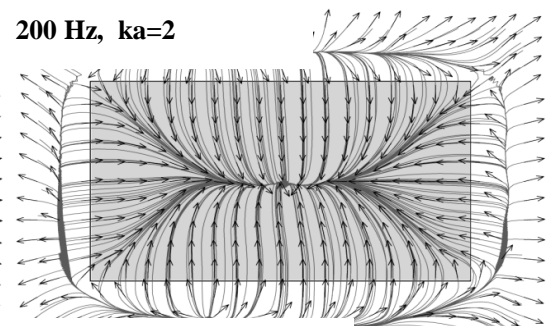

$1000 \mathrm{~Hz}, \mathrm{ka}=10$

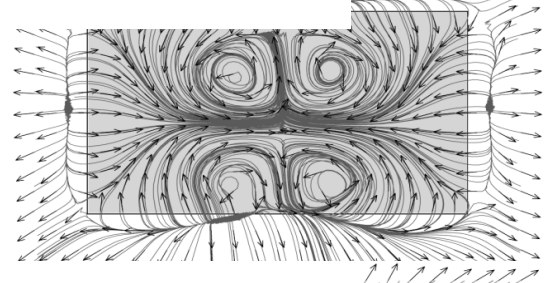

$2000 \mathrm{~Hz}, \mathrm{ka}=20$

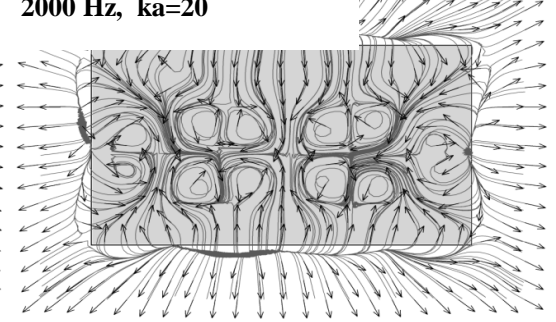

Fig. 3. Sound intensity field as a streamlines in plane close to the rectangular plate

a)

$818 \mathrm{~Hz}$

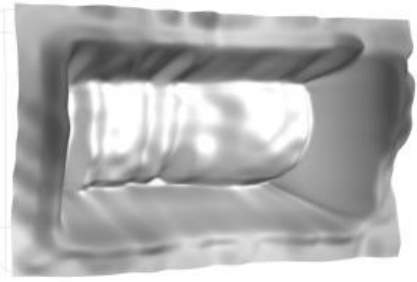

b)

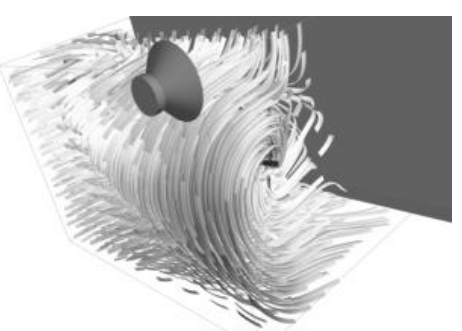

c) $1250 \mathrm{~Hz}, 86 \mathrm{~dB}$

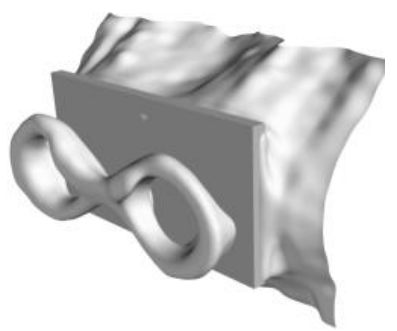

Fig. 4. The sound intensity components for some selected frequencies as a shape of wave in a rear side of plate a), distribution of intensity streamlines around one corner of the plate b) and intensity isosorface around the plate c) 
a)

$630 \mathrm{~Hz}$

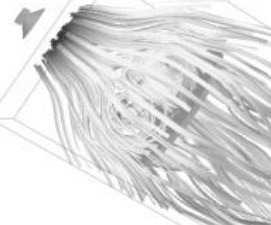

b)

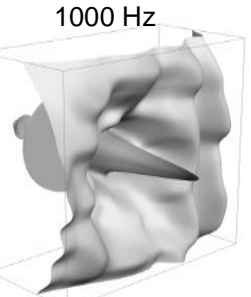

c)

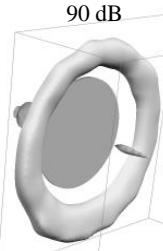

$1000 \mathrm{~Hz}$

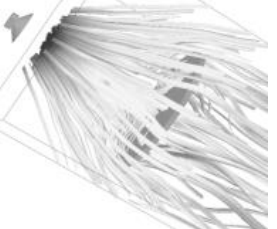

$2000 \mathrm{~Hz}$

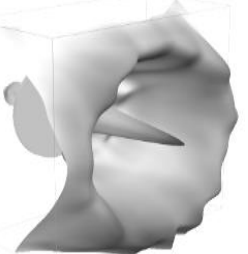

$000 \mathrm{~Hz}$

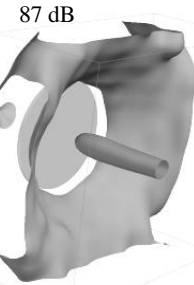

$1600 \mathrm{~Hz}$

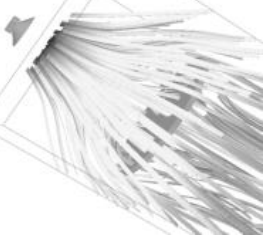

$3150 \mathrm{~Hz}$
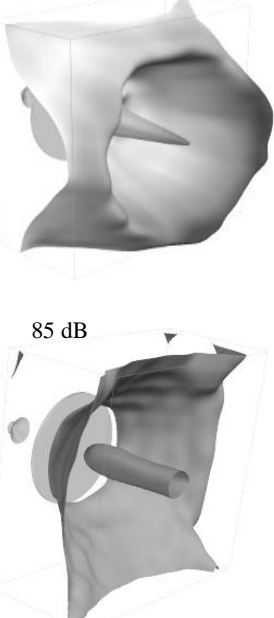

Fig. 5. Acoustic vector fields in space around a disc $d=0.6 \mathrm{~m}$ in form as: a) intensity streamlines, b) shape of shadow wave, c) intensity isosurface

a)
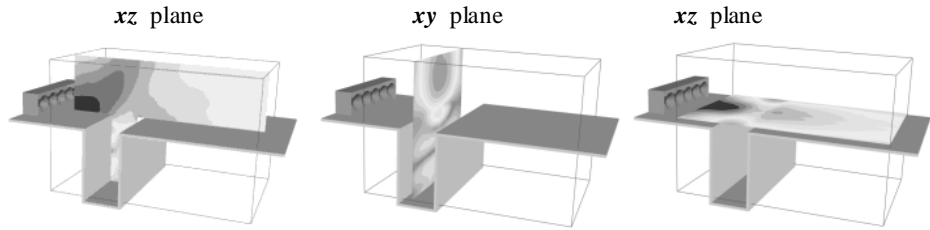

b)

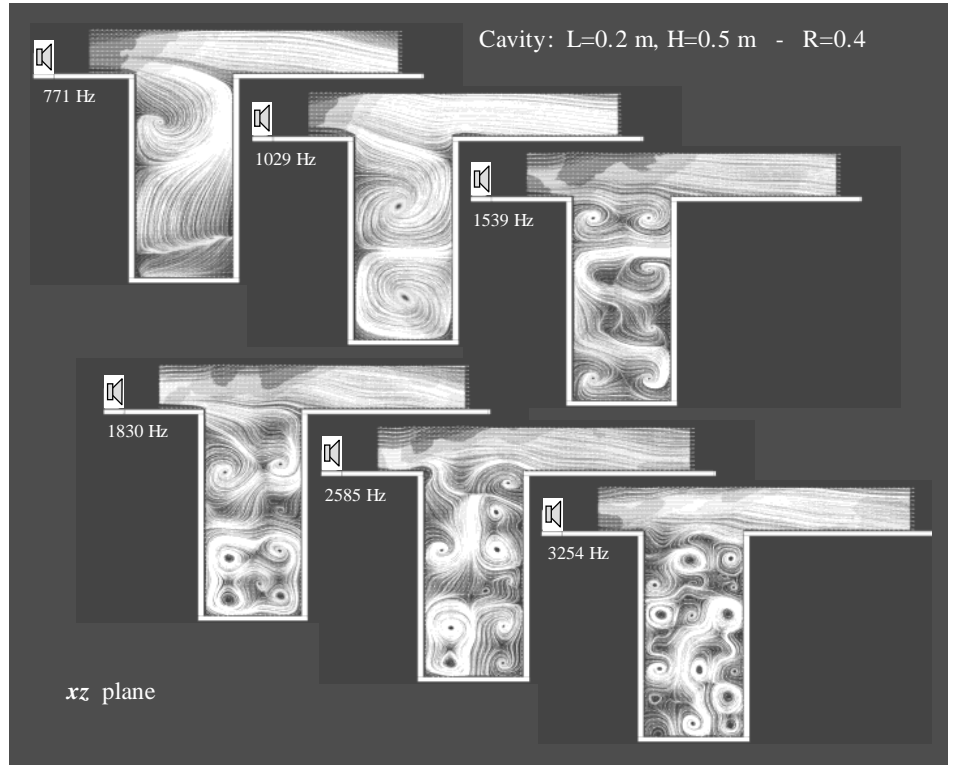

Fig. 6. Distribution of flow field for the loudspeaker line array system radiated over a flat plate with rectangular deep cavity $(0.2 \mathrm{~m}$ wide and $0.5 \mathrm{~m}$ deep $-L / D=0.4$ ): a) intensity map and vectors in the selected measured plane, b) shape of Rossiter modes as intensity streamlines 
The growth and convection of instability waves in the shear layer induce large amplitude pressure disturbances, as the vertical perturbations impinge onto the downstream corner of the cavity. The upstream influence of the generated pressure fluctuations provides further excitation of the instabilities in the shear layer - especially in its most receptive region near the upstream edge.

The tests concern the vector distribution of the field excited by a travelling incident wave coming from a loudspeaker line array system. In the line array, individual radiators - five complete loudspeakers arranged in a straight line (a sound column) - have relatively narrow vertical radiation patterns, which vary strongly with frequency. Attractive as the performance characteristics of line arrays may be, they all have inherent limitations. Firstly, the directivity advantages of a line array are present in the vertical plane only (along the length of the array). The horizontal directivity of a line array is only as good as the performance of the individual devices used to form the array. Secondly, line arrays are made up of discrete elements, as opposed to a continuous line source.

Figures 6 shows part of these studies as a sound intensity field distribution on the plane (a) and also, as streamlines in a three-dimensional investigation space (b). The verifying tests using an intensity technique have shown to what extent the cavity shape influences the shape of the flow field. Note should be given to the vortex effects in the cavity which is frequency dependent.

\section{INTENSITY STREAM FLOW INSIDE AND OUTSIDE OPEN DUCTS}

Most analytical dependencies describing the phenomena occurring in an acoustic field refer to a free- and diffusive field, or possibly an acoustic field in homogeneous ducts at frequencies below cut-off frequencies. For such fields, treated usually as fields with propagating plane waves, the pressure and acoustic intensity are in phase (free field), or as in the case of a diffuse field, interference phenomena are neglected for the frequencies corresponding to wavelengths shorter than the compartment dimensions. In reality, however, there are no compartments, which could be fully qualified as containing free or diffuse fields.

Noise propagation within ducts is of practical concern in many areas of engineering industrial processes, where fluid has to be transported in piping systems as ventilating and air conditioning (HVAC systems), engine exhaust and around gas turbines (Mak and Oldham 1995, Hargreaves et al. 2007). Fan noise and flow noise sources are generated at flow discontinuities or irregularities inside duct systems upstream to the open end. This allows for the determination of noise emission and radiation in free-field environments and correlate the farfield noise levels with aerodynamic noise generation inside the pipes.

The noise produced by a laminar and turbulent flow wave of low Mach number, is studied using the experimental sound intensity technique. The intensity distribution inside a duct is produced by the action of the sum of the modal pressures on the sum of the modal particle velocities. However, the acoustic field is extremely complicated because the pressures in nonpropagating modes (cut-off) cooperate with the particle velocities in propagating modes, and vice versa. By understanding the mechanism of energy transport in the sound channels and pipes, it is possible to find the best solution to noise abatement technology.

Using a sound intensity measurement, a graphical method will be presented to determine the real acoustic wave distribution in a 2D and 3D flow field inside acoustic ducts. Sound intensity generation in hard-walled ducts with acoustic and aerodynamic flow is treated experimentally. The main objective of the study is to provide an understanding of sound-energy transmission by higher-order duct modes. The results will be shown of an acoustic flow inside several models of acoustic open-end waveguides with hard-walled different cross-sections. In open-ended ducts mode shapes and the influence of the cutoff frequency are visualized with sound intensity flow field. The visualization of the results is shown in the form of intensity maps, in a two- and three-dimensional space.

The aim of this study was to obtain information on flows in ducts in order to improve the physical understanding of these flows and to provide well-documented test cases to validate theoretical CFD and CAA models. Finally, we hope that this kind of investigation will contribute to further developments in acoustic-imaging studies to solve acoustic problems in engineering, more reliable technical diagnostics and a more accurate prediction of noise generated by aerodynamic perturbation.

In our work, we have recently proposed an applied sound intensity measurement with a reliable visualization method of acoustic flow in ducts with variable geometry. Sound intensity data recorded inside ducts were considered as a direct measurement of the acoustic flow field and used to visualize the flow waves divided into $1 / 3$ or $1 / 12$ octave band frequencies. Numerous methods of visualization illustrating the power flow as a sound intensity stream can explain graphically standing waves occurring inside ducts, as well as diffraction and scattering phenomena.

The experimental facility sketched in figure 7a has been developed for the study of incoming sound. The ducts are excited by acoustic pink noise, so the sound power along the duct is sent without mean flow.

Figure $7 \mathrm{~b}$ shows the resulting sound intensity vector map in the duct for $200 \mathrm{~Hz}$ and $800 \mathrm{~Hz} 1 / 3$ octave band frequencies. The intensity distribution inside the duct is produced by the action of the sum of the modal pressures on the sum of the modal particle velocities. However, the acoustic field is extremely complicated, because the pressures of non-propagating (cut-off) modes interact with the particle velocities in the propagating modes, and vice versa. The image of the dipolar and quadrupolar sound generated by a flow inside a duct with a square and circular cylinder was obtained using a SI threedimensional Microflown probe and the graphical possibility of our "SIWin" software. In figure 7c we show 2D example of sound intensity in space close to the termination - for frequency $2500 \mathrm{~Hz}$. 
In open-ended ducts, waves reflected from the end play an important part in sound transmission. The back-reflection properties of the opening are specified in terms of the sound intensity field inside the duct and they influence the change of forward-wave amplitude and phase. A wave system in the same mode travels in both directions along the duct and the physical interpretation in terms of forward-wave intensity is only valid above the cut-off frequencies.

Figure 8 shows the results of a 2D sound intensity vector map in the duct termination, as a shape of a flow wave, the intensity isosurfaces and intensity streamlines. Measurements were performed in the space around a rectilinear pipe with circular outlet diameter $D=566 \mathrm{~mm}$, in the frequency band $50-5000 \mathrm{~Hz}$, and were analyzed in $1 / 3$ and $1 / 12$ octave band frequency.

The next experiments are carried out on a straight circular duct serving as an aeroacoustic wind tunnel, in which a fan blower is used to generate a time-uniform mean flow at a very small Mach number (about 0.02). The loudspeaker is placed before the fan at the duct centre. Atmospheric air and/or a pure acoustic wave is supplied into a large $474 \mathrm{~mm}$ diameter and $6 \mathrm{~m}$ long pipe with an open end. Figure 9a shows a sketch of the model of a straight circular duct with an aeroacoustic wind tunnel. The study was conducted in a wide range of frequencies, although the article presents only fragmentary results. The preliminary result, presented in this paper, is only used to validate the experimental procedure and the aeroacoustic test set-up. Based on these findings, modifications of the aeroacoustic wind tunnel design will be carried out in future research.

The space inside the duct was scanned with an intensity probe measuring the $x, y$ and $z$ components of sound intensity vectors. Measurements were made in the frequency band $50-6800 \mathrm{~Hz}$ and analyzed in $1 / 3$ and $1 / 12$ octave band frequency. The flow inside a circular duct provides a physical picture of sound waves in any duct mode; the mode shapes and cut-off frequency are experimentally predicted with sufficient accuracy. The main objective of this analysis is to give a visualization of sound-energy transmission by higher-order duct modes which plays an important role as the noise generating source. The image of the dipolar and quadrupolar sound generated by a flow inside a duct was obtained using an SI three-dimensional USP Microflown probe and a graphical possibility of our 'SIWin' software. In the present experiment, the sound intensity recording was made using a $3 \mathrm{D}$ intensity probe, located inside the duct along the space $2.2 \mathrm{~m}$ long, in the end part of the channel (fig. 10a). In this region, we observed that for the high frequency range (above the cutt-off frequency) the swirling and turbulent flow field was excided downstream the pipe, with acoustic wave generated by a loudspeaker.

The axial standing wave is shown in figure $10 \mathrm{~b}$ as a typical wave according to the acoustic theory. Along the duct, the sound energy carries various modes. Sound propagates in uniform annular ducts mainly by waves spiraling around the duct. The experimental results confirm the occurrence of an axial and swirling flow inside the studied ducts (see fig. 10c-e). These phenomena occur along the whole length of the duct.
A circular flow wave, sometimes called a 'spinning mode', is evident in the range above the cut-off frequency. The swirling modes can get excited in an axisymmetric duct by a disturbance that rotates about the duct axis. The rotations and a swirling wave may occur in high order acoustic modes, which applies both above and below the cut-off frequencies. Therefore, the theory of sound transmission and generation in hard-walled ducts has been extended to include an axial and swirling mean flow. These sound-generating flow-fields are predominantly turbulent. Thus, the prediction of fluid-dynamic or fluid-resonant instabilities and the associated noise radiation, at least at the source generation level, will require in the future an accurate numerical and/or empirical modelling of all ranges of flow scales.

\section{REMARKS AND CONCLUSIONS}

Experimental studies carried out on real models and structures have been documented with graphical records of acoustic fields created by surface sources (radiation of vibrating structures) and the effects of wave interference on obstacles and barriers placed in the flow field. This graphical description allows for the assessment of the effects of the mutual influence of the sources and the examination of the energy distribution of actual acoustic sources.

The analysis of the results makes it possible to obtain important new information about the energetic and geometric distributions of the acoustic fields. Traditional methods of acoustic metrology, based on the acoustic pressure distribution, do not offer such possibilities. The measurement technique described, as well as the method of graphical presentation of results, can enrich the knowledge of the mechanism of acoustic energy flux through real partitions.

The application of the sound intensity method allows for the presentation of the spatial vector real-life conditions of working sources. Acoustic conditions in these areas differ much from the theoretical assumptions ascribed to a free or diffuse field (Richards et al. 2004). It is a frequent occurrence that the sound intensity measurements in real conditions can show great disparity between the theoretical assumptions of the acoustic field distribution and the actual measurements. The disparity results mainly from the simplifications accompanying the analytical methods, due to the lack of complete data concerning physical properties of an investigated object.

The analysis of the acoustic field with a floating wave in space shows that the sound intensity technique is extremely useful in the visualization of vector acoustic phenomena. This form of presentation is new in experimental acoustics. The vector visualization of vibroacoustic phenomena, in contrast to the pressure methods, significantly improves the acoustic diagnostics of machines and devices by a precise localization of noise-radiating sources (hot points). The vector visualization of acoustic fields, controlled in real-life machine operation conditions, allows for the analysis of the radiation energy of the device and its separate structural elements, such as drive circuits and power transmission circuits, and local secondary sources. 
a)

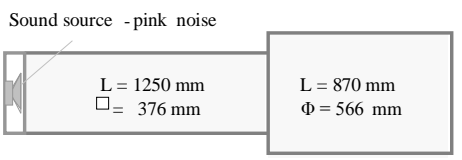

b)

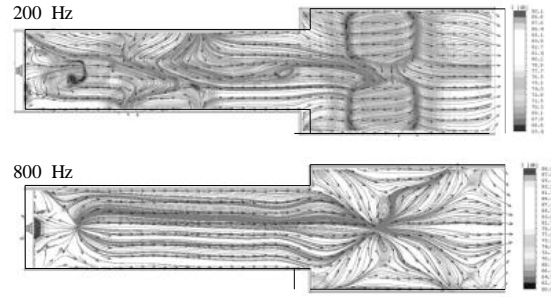

c)

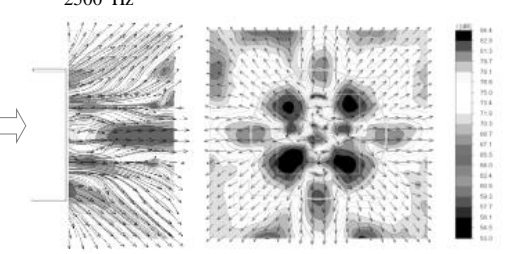

Fig. 7. Set-up of two model of acoustic ducts (a), the maps of sound intensity inside a duct (b) and sound intensity field close termination (c)

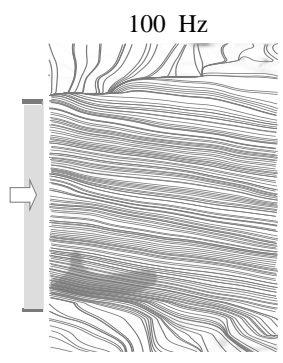

$1000 \mathrm{~Hz}$

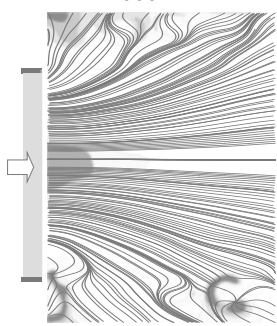

$400 \mathrm{~Hz}$

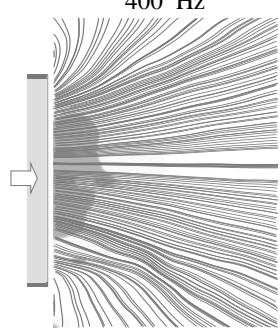

$1600 \mathrm{~Hz}$

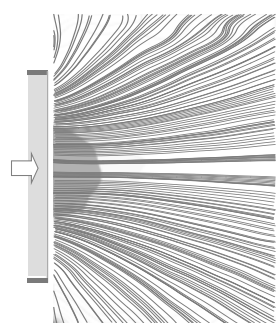

$500 \mathrm{~Hz}$

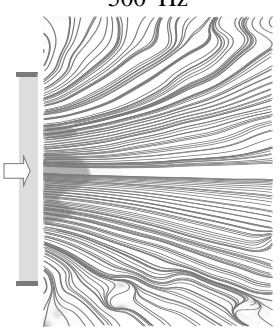

$4000 \mathrm{~Hz}$

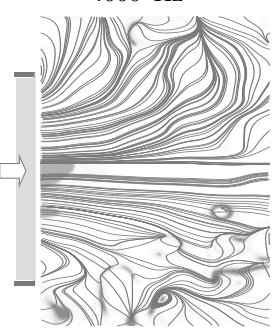

Fig. 8. Vectors map in duct termination as a $2 \mathrm{D}$ shape of floating wave

a)

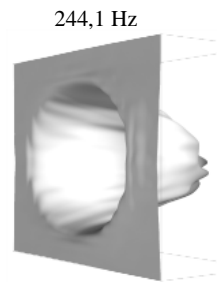

b)

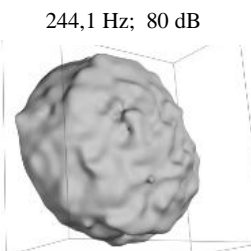

c)

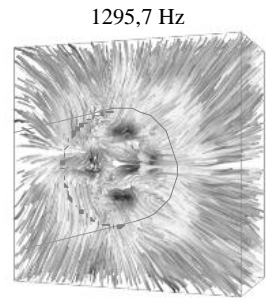

$1295,7 \mathrm{~Hz}$

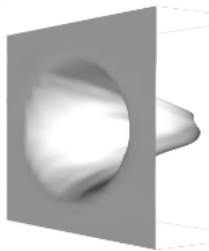

$1295,7 \mathrm{~Hz} ; 79 \mathrm{~dB}$

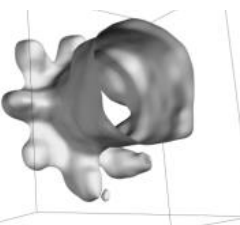

$1631,2 \mathrm{~Hz}$

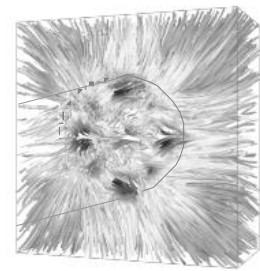

$2440,6 \mathrm{~Hz}$

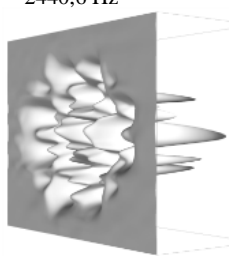

$2440,6 \mathrm{~Hz} ; 80 \mathrm{~dB}$

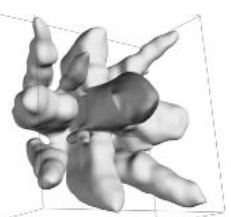

$2440,6 \mathrm{~Hz}$

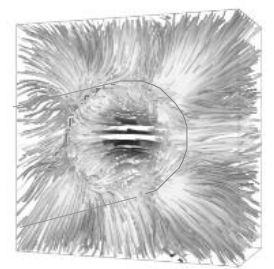

Fig. 9. Distribution of sound intensity in space close termination for some selected frequencies: a) shape of flow wave, b) intensity isosorface in the outlet region, c) intensity streamlines (shown from the rear side of measured space) 


\section{Acoustic waveguide}

a)

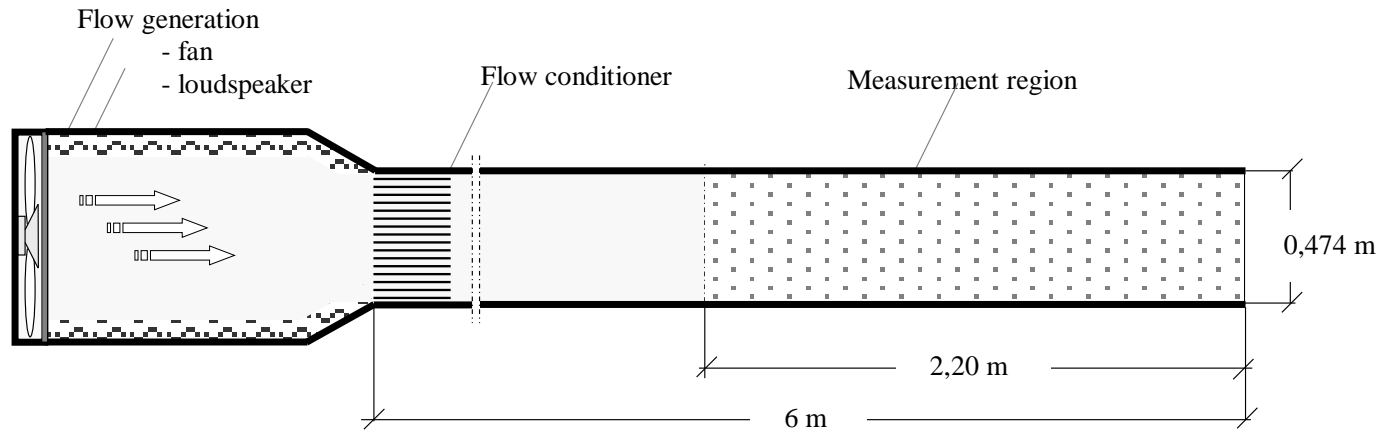

Sound intensity map

b)

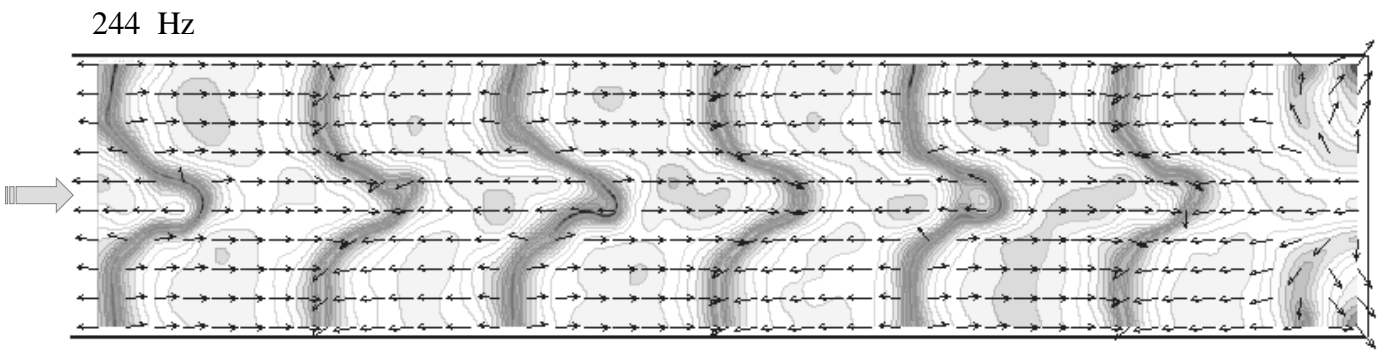

$1600 \mathrm{~Hz}$

c)

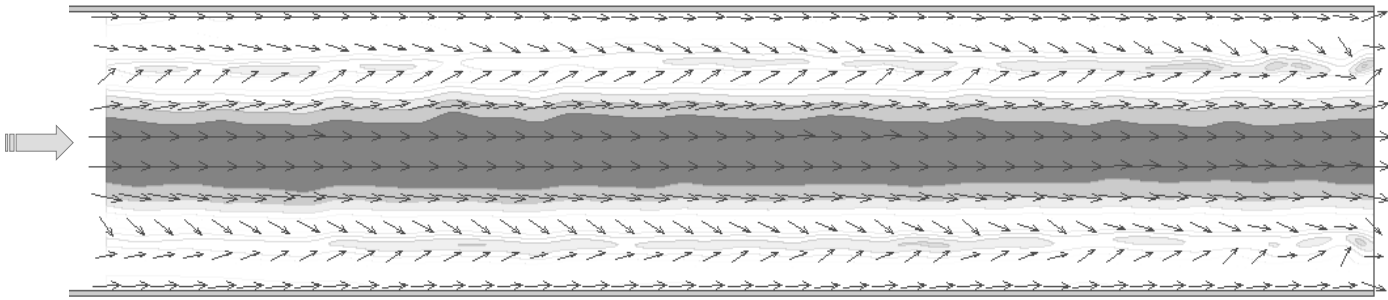

Sound intensity streamlines

d)

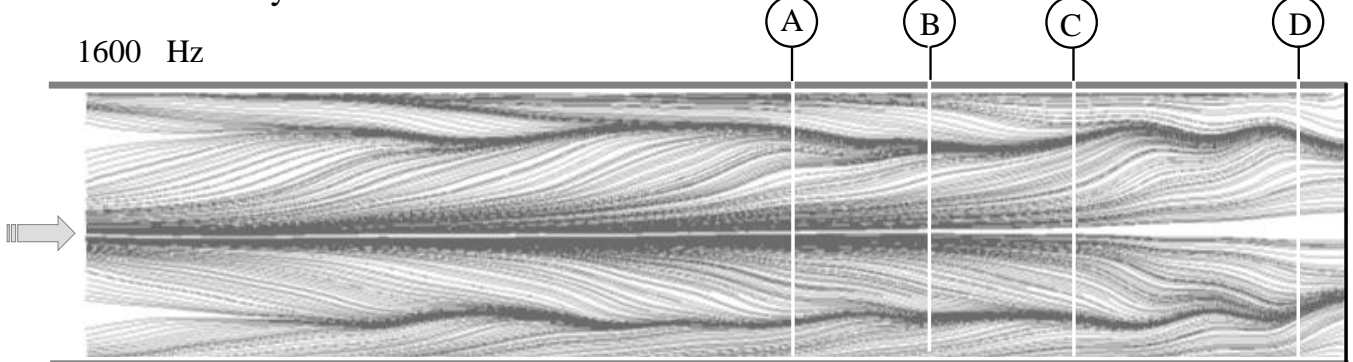

e)

A.

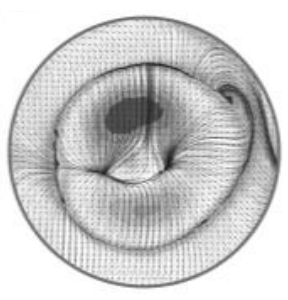

B.

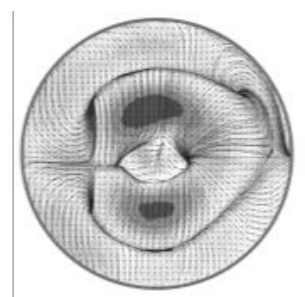

C.

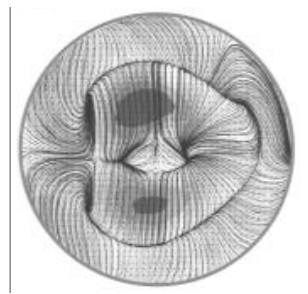

D.

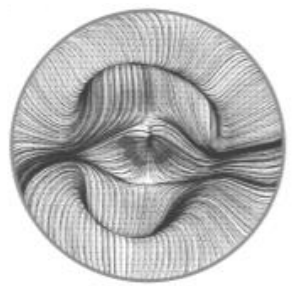

Fig. 10. Acoustic waveguide model and illustration of standing wave (b), high-order mode (c), acoustic flow illustrate by intensity streamlines (d) and radiational mode (e) of an circular open ended duct in region $2.2 \mathrm{~m}$ before end 
The visualization of the research results has been shown in the form of spatial intensity streamlines and as a shape of floating acoustic wave and intensity isosurface in a threedimensional space, which is unavailable by conventional methods using a microphone.

The application of the sound intensity technique together with CFD/CAA methods has improved the quality of acoustic diagnostics and has made it possible to visualize energy wave phenomena (vector distribution) in a vibrating structure, or in an acoustic field around the structure. A precise indication of the local vibration sources is very important in limiting the noise radiated by devices and it enables their structural and parametrical modification.

The direct energy analysis of acoustic fields was not possible earlier because the classical studies used a converter (microphone) measuring pressure changes, and pressure is a scalar descriptor of acoustic waves. Only when direct measurements of sound intensity (as streamlines of acoustic energy a product of acoustic pressure and acoustic particle velocity) became possible, could the wave distribution be analysed in the form of wave acoustic energy transport.

In conclusion, one can say that by the direct measurement of acoustic power flow and a graphical description of the results, it is possible to explain diffraction and scattering phenomena taking place at real acoustical barriers, and to solve in a practical way many scientific and engineering problems. In particular, the flow of acoustic energy represented by the intensity streamlines shows the paths of energy flow in an acoustic field. Showing the paths along which energy is transmitted can be very useful, e.g., when it is necessary to visualize the "pattern of noise" radiated by vibrating mechanical structures (machines, vibrating heterogeneous plates, equipment, etc.), and can show their acoustical activity also in limited 3D spaces.

The presentation of the vector distributions of real acoustic fields in the areas for which it is difficult to make a theoretical analysis (direct field and near field) can explain many particulars concerning the radiation character of surface sources with heterogeneous vibration distributions.

The studies of vector acoustic phenomena carried out in real-life conditions can also be compared with numerical models of acoustic fields, prepared with commercials software available on the market. Experimental investigations indicate that simplifications used in the simulation numerical models result in serious disparities between theory and real-life data (Weyna 2007), (Weyna 2009). In such cases the sound intensity studies carried out on physical models can serve to link theory with practice, by imposing limits on allowable reductions of the fluid-structure interactions (FSI) effects in real-life physical fields.

\section{References}

Crighton D.G. et al., 1966, Modern Methods in Analytical Acoustics. SpringerVerlag, London.

Dickinson R.R., 1989, A unifield approach to the design of visualization software for the analysis of field problems. Proc. Three-dimensional Visualization and Display Technologies, Spie, 173-180.
Fahy F.J., 1989, Sound Intensity. Elsevier Applied Science, London.

Ffowcs Williams J.E., 1996, Aeroacoustics. Journal of Sound and Vibration, 190(3), 387-398.

Gerald-Yamasaki M., 1995, Visualization of Computational Fluid Dynamics. CFD Revue 1995.

Gloerfelt X., Bailly C., Juve D., 2003, Direct computation of the noise radiated by a subsonic cavity flow and application of integral methods. Journal of Sound and Vibration, 266(1), 119-146.

Hafez M., Oshima K., 1995, Computational Fluid Dynamics Review. John Wiley \& Sons, Chichester.

Hargreaves D.M., Morvan H.P., Wright N.G., 2007, Validation of the volume of fluid method for free surface calculation: the broad-crested weir. Engineering Applications of Computational Fluid Mechanics, vol. 1, no. $2,136-164$.

Lighthill M.J., 1952, On sound generated aerodinamically - I. General theory. Proc. of the Royal Society A 211, 564-587.

Mak C.M., Oldham D.J., 1995, The application of computational fluid dynamics to the prediction of regenerated noise in ventilation system. Inter-Noise, Newport Beach, CA, 281-284.

Munson B.R., Young D.F., Okiishi T.H., 1990, Fundamentals of Fluid Mechanics. Wiley, New York.

Raffel M., Willert C., Kompenhans J., 1998, Particle-image Velocimetry. A Practical Guide. Springer, Heidelberg.

Richards S.K., Zhang X., Chen X.X., Nelson P.A., 2004, The evaluation of non-reflecting boundary conditions for duct acoustic computation. Journal of Sound and Vibration, 270, 539-557.

Wagner C., Huttl T., Sagaut P., 1989, Large-eddy Simulation for Acoustics. Cambridge Univ. Press, Cambridge.

Weyna S., 2007, Some comments about the existing theory of sound with comparison to the experimental research of vector effects in real-life acoustic near fields. Archives of Acoustics vol. 32, no 4, 441-451.

Weyna S., 2009a, Experimental study of sound propagation in open duct with variable geometry. 16-th International Congress on Sound and Vibration, ICSV16, Kraków 2009, S-187.

Weyna S., 2009b, Visualization method of acoustic wave propagation in reallife conditions. The First International Conference on Soft Computing Technology in Civil, Structural and Environmental Engineering. Madeira 2009 Civil-Comp Press, 97-104.

Weyna S., 2010a, Acoustic intensity imaging methods for in-situ wave propagation. Archives of Acoustics. 35(2), 2010, 265-273.

Weyna S., 2010b, An acoustics intensity based investigation of the energy flow over the barriers. Acta Physica Polonica A vol. 118, 172-178.

Weyna S., 2011, Acoustics flow visualization method - seeing the invisible. Proc. The 8th International Conference on Fuzzy systems and Knowledge Discovery, Shanghai.

Weyna S., 2012a, Acoustics flow field visualization using sound intensity and laser anemometry methods. XX Fluid Mechanics Conference KKMP2012, Gliwice, 27-2.

Weyna S., 2012b, Visualization method of acoustic wave propagation based on the sound intensity measurement. Chapter in: Nowicki A. (ed.), Acoustic Imaging. Springer, vol. 31. 243-252.

Weyna S., 2013, Visualizations of the subsonic acoustic wave flow inducing noise inside open ducts. Proc. 20th International Congress on Sound and Vibrations, ICSV20, Bangkok.

Weyna S., 2014, Acoustics flow analysis in circular duct using sound intensity and dynamic mode decomposition. XXI Fluid Mechanics Conference, Journal of Physics: Conference Series 530 (2014), 012046.

Weyna S., Mickiewicz W., Pyła M., Jabłoński M., 2013, Experimental acoustic flow analysis inside a section of an acoustic waveguide. Archives of Acoustics, vol. 38(2), 211-216.

Williams E.G., 1999, Fourier Acoustics - Sound Radiation and Nearfield Holography. Academic Press. San Diego, London, New York.

Zhang Zh., 2010, LDA Application Methods - Laser Doppler Anemometry for Fluid Dynamics. Springer. 